\title{
Development of flavor aversions by rats following anesthesia
}

\author{
STEPHEN H. HOBBS \\ Augusta College, Augusta, Georgia \\ and \\ RALPH L. ELKINS \\ Veterans Administration Medical Center, Augusta, Georgia
}

\begin{abstract}
A series of experiments was conducted which confirmed an earlier report that rats may develop aversions to novel flavors initially presented to them up to 2 days following surgery. Results further suggested that this effect is primarily due to anesthesia induction and that it is responsive to type of anesthetic, age of subjects, and time factors. The phenomenon is hypothesized to be an associative one that has design implications for studies involving surgical interventions.
\end{abstract}

The acquisition and retention of conditioned aversions to foods and/or fluids has received considerable attention in recent years, with some researchers using the lesion technique to explore the neural mechanisms of these learned aversions. In one such study (Hobbs \& Elkins, 1976), evidence suggested that commonly used surgical control procedures may themselves produce in rodents internal malaise sufficient to cause a conditioned flavor aversion. In that study, one group of rats was given sham operative procedures following the initial determination of a preference for saccharin-flavored water over plain tap water. After 2 days of surgical recovery, the animals were again given continuous access to both tap water and the saccharin solution. Of the five animals in this group, three developed strong aversions to the saccharin fluid within the first 3 days of testing. Since the aversions were not present at the time of the initial test or on the 1st day of postsurgical testing, we concluded that the rats were not neophobic and also that they had not formed an association between the initial experience with saccharin and the subsequent malaise associated with surgery. Rather, we hypothesized that the animals had formed an aversive association between persisting surgically related stress and the postoperative drinking of the still relatively novel saccharin stimulus.

\section{EXPERIMENT 1}

Since sham surgery is a necessary control feature in lesion studies, it was deemed important to further investigate its possible effect on dietary shifts. We were, therefore, initially interested in attempting to replicate our

This work was supported in part by the Medical Research Service of the Veterans Administration. Please direct reprint requests to the first author, Department of Psychology, Augusta College, Augusta, GA 30910. previous observation, but without the confounding presurgical exposure to saccharin. Additionally, we wanted to determine if inducing anesthesia alone (without surgery) was sufficient to produce a flavor aversion.

\section{Method}

Twenty-six experimentally naive male albino rats obtained from ARS/Sprague-Dawley served as subjects. They were housed individually under controlled temperature and a 12:12 light-dark cycle (lights on at $0600 \mathrm{~h}$ EST). They ranged in age, at the beginning of the study, from 181 to 197 days. Body weighings and bottle weighings (to determine fluid intake) were made daily between 1300 and $1400 \mathrm{~h}$ EST.

The rats were assigned randomly to one of four experimental conditions. During lights-on hours, six animals were injected intraperitoneally (ip) with isotonic saline $(3.75 \mathrm{cc} / \mathrm{kg})$; six were injected ip with an illness-inducing agent, Cytoxan (cyclophosphamide; $50 \mathrm{mg} / \mathrm{kg}, 3.75 \mathrm{cc} / \mathrm{kg}$ ); seven were given an ip injection of Equithesin anesthetic $(3.75 \mathrm{cc} / \mathrm{kg})$; and seven were given typical sham surgical treatment following Equithesin anesthesia administration. Sham surgery involved the removal of the bone flap over the olfactory bulbs without penetration of the dura mater. Additional anesthesia was not required for any sham-surgery animal.

Continuous saccharin preference testing began $48 \mathrm{~h}$ later and extended across 13 days. Two bottles, one containing tap water and the other a $.05 \%(\mathrm{w} / \mathrm{v})$ solution of sodium saccharin, were placed on the front of each home cage. Bottle positions were reversed daily. Preference scores were computed daily by dividing the amount of saccharin intake by the total amount of fluid ingested.

Weighted-means solutions for unequal groups were employed in analyses of variance, and individual comparisons were made using the Newman-Keuls procedure (Winer, 1962).

\section{Results}

Although all subjects survived the course of the experiment, fluid and body-weight measures indicated that treatments differentially produced illness effects. Body-weight data are presented in Figure 1. Prior to treatment, there was considerable within- and between-group weight variability, but the groups did not differ statistically. An analysis of variance of body weights after injections, however, did find a significant group effect $(p<.01)$, as well as 


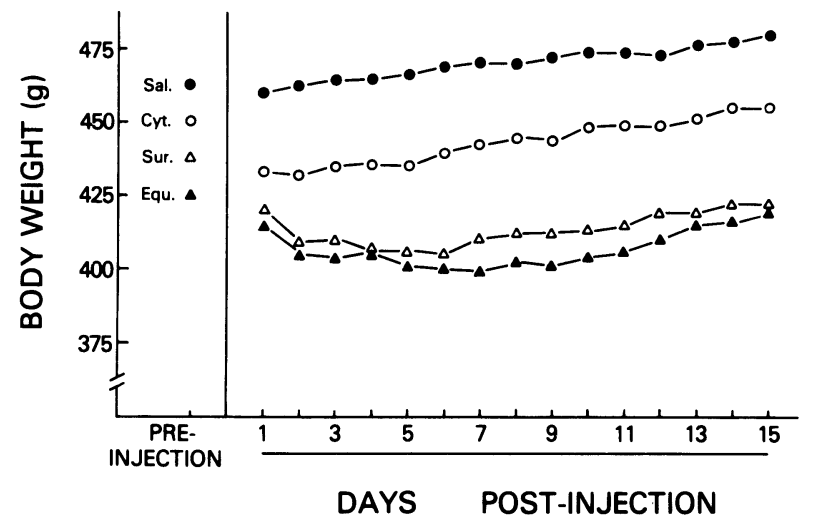

Figure 1. Mean group body weights on the day preceding treatments and for the 15 days following injections.

days $(\mathrm{p}<.01)$ and interaction $(\mathrm{p}<.05)$ effects. Although weight reductions occurred in every animal but one (in the saline group) on the 1st posttreatment day, greater and more persistent weight losses were found in the surgery and Equithesin groups. At the time of the initial posttreatment weighing, the saline group had lost less weight than any other group (each $p<.01$ ), but the other groups did not differ among themselves. By the end of the preference testing period, only the Equithesin and surgery animals had, as a group, not surpassed pretreatment bodyweight levels. Statistically, these two groups still had significantly lowered weight relative to the saline group (each $\mathrm{p}<.05$ ); the saline and Cytoxan groups did not differ. The only other significant difference obtained at this time was between the Cytoxan and Equithesin groups $(\mathrm{p}<.05)$.

A single 24-h measure of water consumption prior to two-bottle testing (Figure 2) resulted in significant group differences $(p<.01)$. Individual comparisons revealed that the surgery and Equithesin groups drank significantly less water than the saline group and that the surgery group consumed less than the Cytoxan group (all ps $<.01$ ). Other group comparisons were nonsignificant.

Total fluid intake during two-bottle preference testing is also presented in Figure 2. An analysis of variance confirmed significant overall group effects $(p<.01)$. The two groups receiving anesthesia each had significantly less total fluid intake than each of the other groups (ps $<.05$ or better). No other comparisons approximated statistical significance.

The saccharin preference scores for each group across the two-bottle testing period are depicted in Figure 3. An analysis of variance performed on these data revealed significant group, days, and group $\times$ days effects (each $p$ $<.01)$. Individual comparisons indicated that the salineand cyclophosphamide-injected animals were not different from one another, but that these two groups each had greater saccharin preference than the remaining two groups (each $\mathrm{p}<.01$ ). Additionally, the preference scores evidenced by the anesthesia-only animals were sig- nificantly lower than those of animals receiving sham surgery $(\mathrm{p}<.05)$.

\section{EXPERIMENT 2}

Experiment 1 confirmed our previous observation of postsurgical flavor aversion development and suggested that the effect was primarily attributable to anesthesia induction. It is important to emphasize that, under the parameters used above, cyclophosphamide-induced illness did not produce subsequent aversions. Also, the preference shift does not simply reflect reduced fluid intake. For example, aversions persisted beyond the onset of fluid intake recovery, and Equithesin animals developed aversions greater than those of the surgery group in spite of having similar reductions in overall fluid intake. Finally, it was now clear that the aversion development does not result from prior exposure to a saccharin solution as provided in the Hobbs and Elkins (1976) study.

Equithesin, the anesthetic used in the first experiment, contains two primary active agents, chloral hydrate and pentobarbital sodium. Another commonly used anesthetic, Nembutal, employs only pentobarbital as its hypnotic component. Experiment 2 was undertaken as a direct comparison of Equithesin and Nembutal in producing subsequent saccharin aversions. Also compared were the effects of either a 1- or 14-day interval between anesthesia induction and the beginning of saccharin access. The longer interval was chosen as one frequently employed by researchers for a surgical recovery period preceding behavioral testing.

\section{Method}

Thirty male Sprague-Dawley rats obtained from Flow Research were housed as in Experiment 1. The animals were experimentally naive and approximately 90 days old at the beginning of the experiment.

The animals were assigned randomly to one of three conditions in which equal numbers of rats were injected ip with Nembutal

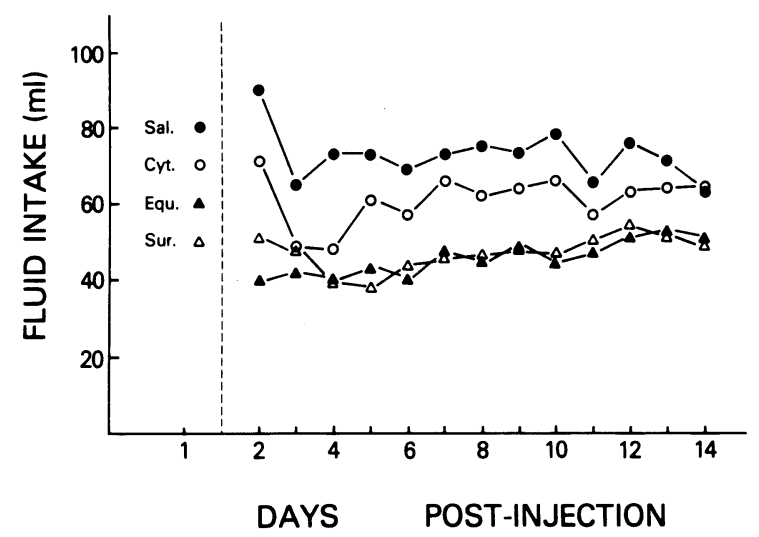

Figure 2. Mean group water intake (single bottle) on the day following injections and total fluid intake (water plus saccharin) on the remaining posttreatment days. Days designate the beginning of each 24-h test interval. 


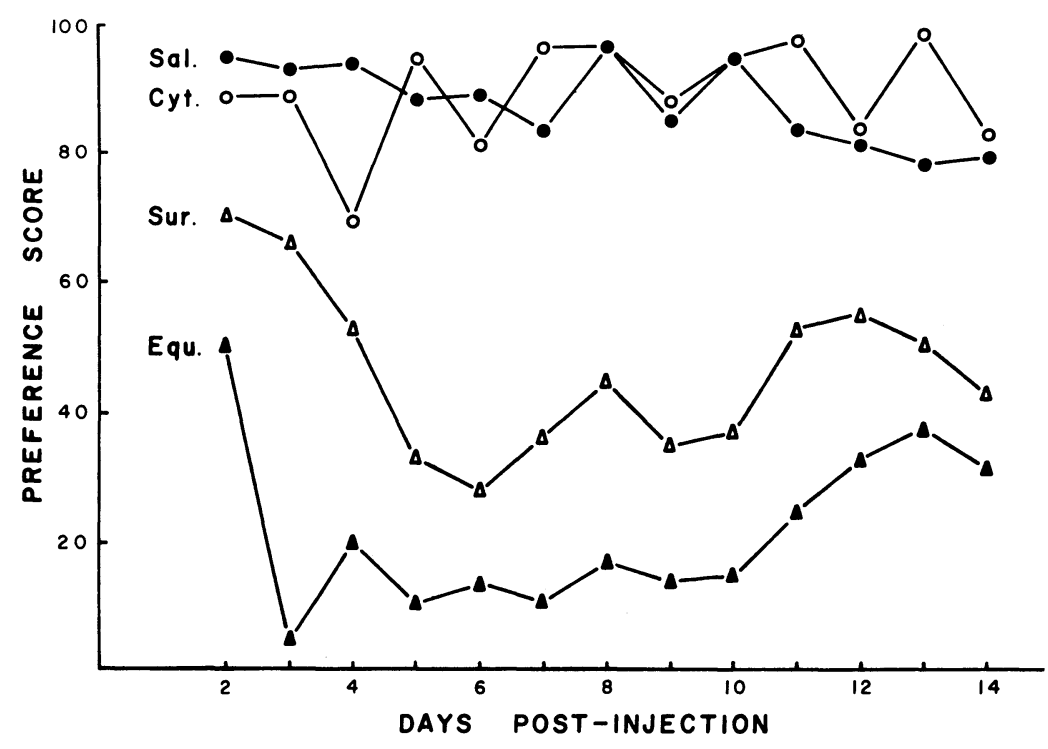

Figure 3. Mean group saccharin preference scores across testing. Days designate the beginning of each $24-\mathrm{h}$ test interval.

$(60 \mathrm{mg} / \mathrm{kg}, 1.20 \mathrm{ml} / \mathrm{kg})$, Equithesin $(3.75 \mathrm{ml} / \mathrm{kg})$, or isotonic saline $(3.75 \mathrm{ml} / \mathrm{kg})$. Anesthetic dosages were selected on the basis of sampling from other studies and our own experience in achieving reliable surgical anesthesia in adult rats. An experimenter, blind to group assignment, determined if surgical anesthesia had been obtained by use of tail-pinch and eye-blink reflex tests and noted the number of minutes from injection that muscle tone (scratching, chewing, twitching, head erection, etc.) began to return to subjects in the two anesthetized groups. The subjects were then returned to their cages with free access to food and water.

Two-bottle saccharin preference testing, as in Experiment 1, was conducted for 5 consecutive days, with the initial test beginning either 1 or 14 days postinjection. Thus, five animals were included in each of the six combinations of injection and test-delay conditions.

\section{Results}

All Equithesin and Nembutal subjects achieved a level of anesthesia sufficient for surgery. Furthermore, the two anesthesia groups did not differ statistically in the rated number of minutes to return of muscle tone. The mean for the Equithesin subjects was 144.5 min (range, 105$255 \mathrm{~min}$ ) and that for the Nembutal subjects was 132.0 min (range, 40-205 min).

Anesthetized animals had reduced fluid intake and body weight immediately following injections, but there were no statistically significant differences between the Equithesin and Nembutal groups. Increases in both of these measures for all groups was obtained beginning 2 days after injections. Preinjection body-weight levels were achieved by anesthetized groups within 4 days, and the daily onebottle water intake of the 14-day-delay anesthetized groups was comparable to that of their saline controls, also within 4 days.

The preference-score data are presented in Figure 4. An analysis of variance revealed no statistically significant effects other than an interaction between injection and delay conditions $(p<.01)$. Individual comparisons subsequently indicated that the subjects anesthetized with
Equithesin and presented with saccharin the following day had lower preference scores than either the Equithesin or saline groups from the 14-day-delay condition (each $\mathrm{p}<.05$ ). Other comparisons failed to reach conventional levels of statistical significance.

\section{EXPERIMENT 3}

The foregoing experiment led to two tentative conclusions. First, although the exact temporal parameters of the anesthesia effect on fluid preferences was not pinpointed, the commonly used 2-week surgical recovery period might be sufficient to prevent such shifts. Specifically, the Equithesin animals exposed to saccharin 1 day following anesthesia developed saccharin aversion (preference scores < 50) whereas their 14-day-delay counterparts did not. The aversion effect, however, was weak in that the Equithesin versus saline, Day 1 preference scores failed to reach conventional levels of significance

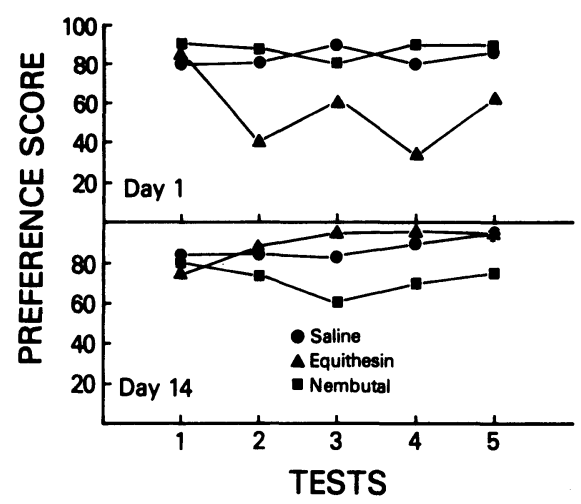

Figure 4. Mean group saccharin preference scores across 5 days of testing for groups tested beginning the day following injections (upper panel) and 14 days after injections (lower panel). 
(see discussion below). Second, it appeared that not all anesthetic agents were equally capable of eliciting aversion development. This interpretation, too, must be considered cautiously, since dosages were not empirically equated beyond routine experience and since no main effect between the anesthetic agents was obtained. However, the potential significance of such a difference for researchers led us to again compare the effects of Equithesin, Nembutal, and saline injections in Experiment 3. In order to assess the generalizability of the phenomenon previously obtained, a milk solution was substituted for saccharin in the preference tests.

A second change resulted from an analysis of the weaker Equithesin-produced aversions in Experiment 2 relative to those obtained in Experiment 1, even though the anesthesia-testing delay interval had been shortened to 1 day. One of the several factors that might have contributed to this finding was the younger age of the subjects in Experiment 2 (90 days) relative to those in Experiment 1 (181-197 days) and those in Hobbs and Elkins (1976) (180 days). Although young adult rats generally acquire stronger taste aversions than rat pups (e.g., Baker, Baker, \& Kesner, 1977; Caza, Steinert, \& Spear, 1980), there is no clear evidence that aversion strength is enhanced by further maturation (Franchina \& Horowitz, 1982; Guanowsky \& Misanin, 1983). Nevertheless, we returned to the use of older subjects in the next experiment.

\section{Method}

Eighteen male Sprague-Dawley rats (Flow Research), approximately 250 days old at the start of the experiment, were housed and maintained as previously described.

Equal numbers of subjects were injected ip with saline, Equithesin, or Nembutal, as in Experiment 2. Beginning $24 \mathrm{~h}$ after injections and continuing for 10 days, each subject was given access to two bottles, one containing tap water and the other a $3 \%$ solution $(w / v)$ of Carnation instant milk in tap water. Daily preference scores were computed to reflect the percentage of milk consumed relative to all fluid consumed.

\section{Results}

Perhaps not surprisingly, greater anesthesia-related problems occurred in these older subjects. Of the six animals in the Nembutal group, three developed respiratory distress, with one failing to survive resuscitation efforts. Equithesin-injected subjects did not have any similar problems, although one animal did not reach a surgical level of anesthesia. The mean rated time for muscle tone to recover was $242.0 \mathrm{~min}$ for the remaining animals in the Nembutal group (range, 125-440 min) and 164.2 min for the Equithesin group (range, 15-225 min). This difference was statistically nonsignificant.

Only the anesthetized groups had body-weight losses on the day following injections, but these group differences were not statistically significant. Although weight reductions were initially greater for the Nembutal animals, the Equithesin animals ultimately had a greater percentage of weight loss, took longer to begin weight gain, and took longer to achieve preinjection body weight than the
Nembutal group. Again, these were trends that did not reach statistical levels of significance.

The milk-preference scores are presented in Figure 5. A two-way ANOVA of these data yielded statistically significant effects of injection conditions and repeated measures (each $p<.01$ ) but no interaction effect. Individuals comparisons showed that the milk-preference scores for the Equithesin animals were lower than those for the saline-injected $(p<.01)$ and Nembutal-injected animals $(\mathrm{p}<.05)$. The difference between the Nembutal and saline groups failed to reach significance $(.05<\mathrm{p}<.10)$.

If milk aversion is arbitrarily defined as at least 3 consecutive days of preference scores of less than 50, the number of animals avoiding milk in the saline, Equithesin, and Nembutal groups, respectively, were one, six, and two. The two subjects in the Nembutal group that showed aversions were the same animals that had respiratory problems after injection and took the longest to regain muscle tone.

\section{Discussion}

The greater milk rejection by anesthetized rats in the present study demonstrated that the reported preference shift was not specific to a single taste solution (saccharin). The results from this experiment were also consistent with those from Experiment 2 in that Equithesin seemed to potentiate aversion development more easily than Nembutal. The reason for this difference is not clear, but the addition of chloral hydrate in Equithesin would be one obvious possibility. Irrespective of anesthetic, depth of anesthesia and respiratory distress are, by themselves, insufficient explanations of subsequent aversion development. Better indices would appear to be more straightforward measures of internal malaise, such as time to recover normal amounts of eating and drinking.

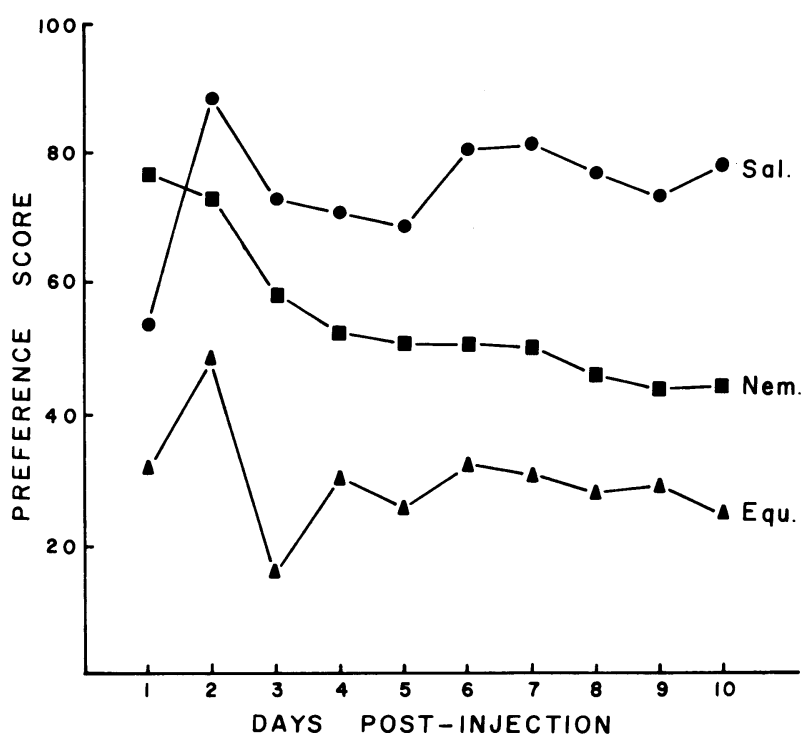

Figure 5. Mean group milk preference scores across testing. 


\section{GENERAL DISCUSSION}

The results of these three experiments clearly demonstrate the reliability of the phenomenon initially reported as an incidental finding by Hobbs and Elkins (1976). That is, a relatively novel fluid may become aversive to an animal if it is made available shortly after surgery. It is now also apparent that anesthesia alone may evoke the aversion, and that increasing the drug-flavor interval reduces or eliminates aversion development. Finally, the effect may be weaker with some anesthetics and with younger animals.

The implications of these findings for physiological/behavioral research should be manifest. The practice of allowing animals an adequate recovery period following surgery (or similar intervention) has obvious merit. Certain questions, however, can be answered only with designs calling for rather immediate postsurgical or postdrug behavioral testing. Especially in those cases where relatively novel or distinctive flavors are presented, researchers need to be cognizant of the potential for aversion development.

Since we were primarily interested in determining the reliability of this aversion effect and some of the conditions under which it might occur, we have yet to deal directly with whether the basis of the aversion is truly associative or if it perhaps results from a drug-enhanced neophobic or pseudoconditioning response. We favor the first alternative, primarily on the basis of observation that the phenomenon shares the following characteristics with conditioned flavor aversions.

First, the components of the anesthetics used in our studies (chloral hydrate and pentobarbital) are two of the many hypnotic agents previously shown to have the ability to produce conditioned flavor aversions (e.g., Brown \& Glusman, 1971; Burešová \& Bureš, 1977; Goudie \& Dickins, 1978; Roll \& Smith, 1972; Rozin \& Ree, 1972; Vogel \& Nathan, 1975). The potential for a sedative (but not anesthetic) dose of pentobarbital to establish aversions has also been reported (Revusky, Taukulis, Parker, \& Coombes, 1979).

Second, many of the anesthetized animals in our experiments did not show immediate rejection of the novel fluid as would be expected with a neophobic response. The averaged data presented in Figures 3-5 conceal the fact that some drug-injected animals did not evidence target fluid rejection until 4-6 days after the beginning of preference testing. This might be expected if drinking the still relatively novel stimulus (saccharin or milk) were paired with the enduring effects of anesthesia. Although "illness" does precede the flavor in our experiments and backward conditioning has been reported for taste aversions, aversions did not develop in the cyclophosphamideinjected animals of the first experiment, even with their mild water-intake and body-weight reductions. Therefore, it appears that the continuation of substantial malaise into the time of exposure to the flavor gives the phenomenon the power of typical conditioned flavor-aversion paradigms.
If residual illness does, indeed, account for the development of flavor aversions in the anesthetized animals, one might have expected that the additional trauma of surgery would have created even stronger aversions. In spite of even greater (but nonsignificant) weight losses by the surgical group (Experiment 1), however, the contrary occurred. The most simple explanation for this finding stems from previous research (e.g., Garcia \& Ervin, 1968; Garcia \& Koelling, 1966), which has shown that consummatory behaviors are more likely to be associated with internal, visceral events than with external, "surface" events. At a more cognitive level, an ill animal with a head wound may less readily blame its malaise on ingestibles than an ill animal with no such cutaneous stimulation. It might also be predicted that sham-operated animals would develop stronger place avoidance behaviors than those only anesthetized, but no evaluation of such a possibility was made.

Finally, it should be noted that, in our 1976 study, the sham-operated animals that subsequently developed aversions served as controls for an identically treated group of rats which had sustained bilateral lesions of the olfactory bulbs. In congruence with other studies which have determined that such lesions block the acquisition of conditioned taste aversions (e.g., Dinc \& Smith, 1966; Elkins, Fraser, \& Hobbs, 1977; Hankins, Garcia, \& Rusiniak, 1973), none of the bulbectomized animals developed saccharin aversions. That is, the lesion appears to have blocked an associative process.

Further experimentation is obviously required to better understand the nature of the aversions reported here. Of the many questions possible, let us raise these few: (1) Does anesthetization produce a transient neophotic response not detected by our 24-h intake measures? (2) Would anesthetized animals reject the more novel of two stimulus solutions? (3) Which of the many anesthetics (or anesthesia procedures) might be best suited for experiments requiring short postsurgical intervals? (4) Would rats selectively bred for proneness or resistance to develop conditioned taste aversion (Hobbs \& Elkins, 1983) similarly distinguish themselves if presented with a novel flavor following anesthetization?

\section{REFERENCES}

Baker, L. J., BAKer, T. B., \& Kesner, R. P. (1977). Taste aversion in young and adult rats. Journal of Comparative and Physiological Psychology, 91, 1168-1178.

Brown, D. L., \& Glusman, M. (1971). Conditioned gustatory aversion with anesthetic and convulsive agents. Psychonomic Science, 25, 49. (Abstract)

BUREŠ́vÁ, O., \& BUREš, J. (1977). The effect of anesthesia on acquisition and extinction of a conditioned taste aversion. Behavioral Biology, 20, 41-50.

Caza, P., Steinert, A., \& Spear, N. (1980). Comparison of circadian susceptibility of $\mathrm{LiCl}$-induced taste aversion learning between preweanling and adult rats. Physiology \& Behavior, 25, 389-396.

Dinc, H., \& SMITH, J. (1966). Role of the olfactory bulbs in the detection of ionizing radiation by the rat. Physiology \& Behavior, 1, 139-144.

Elkins, R. L., Fraser, J., \& Hobbs, S. H. (1977). Differential olfac- 
tory bulb contributions to baitshyness and place avoidance learning. Physiology \& Behavior, 19, 787-793.

Franchina, J. J., \& Horowitz, S. W. (1982). Effects of age and flavor preexposures on taste aversion performance. Bulletin of the Psychonomic Society, 19, 41-44.

GarCIA, J., \& ERvin, F. R. (1968). Gustatory-visceral and telereceptorcutaneous conditioning-adaptation in internal and external milieus. Communications in Behavioral Biology, 1, 389-415.

GARCIA, J., \& KoELling, R. A. (1966). Relation of cue to consequence in avoidance learning. Psychonomic Science, 4, 123-124.

GoudIE, A., \& DickINS, D. (1978). Nitrous oxide-induced conditioned taste aversions in rats: The role of duration of drug exposure and its relation to the taste aversion self administration "paradox." Pharmacology, Biochemistry \& Behavior, 9, 581-592.

GuANOWSKY, V., \& MisaniN, J. R. (1983). Retention of conditioned taste aversion in weanling, adult, and old-age rats. Behavioral and Neural Biology, 37, 172-178.

Hankins, W., Garcia, J., \& RusiniaK, K. (1973). Dissociation of odor and taste in bait shyness. Behavioral Biology, 8, 407-419.

HobBs, S., \& ElKINS, R. L. (1976). Bait shyness retention in rats with olfactory-bulb ablations. Physiological Psychology, 4, 391-394.
HobBS, S. H., \& ElKins, R. L. (1983). Operant performance of rats selectively bred for strong or weak acquisition of conditioned taste aversions. Bulletin of the Psychonomic Society, 21, 303-306.

Revusky, S., Taukulis, H., Parker, L., \& Coombes, S. (1979). Chemical aversion therapy: Rat data suggest it may be countertherapeutic to pair an addictive drug state with sickness. Behavior Research and Therapy, 17, 177-188.

Roll, D., \& SMITH, J. (1972). Conditioned taste aversion in anesthetized rats. In M. Seligman \& J. Hager (Eds.), Biological boundaries of learning. New York: Appleton-Century-Crofts.

RozIN, P., \& REE, P. (1972). Long extension of effective CS-US interval by anesthesia between CS and US. Journal of Comparative and Physiological Psychology, 80, 43-48.

Vogel, J., \& NATHAN, B. (1975). Learned taste aversions induced by hypnotic drugs. Pharmacology, Biochemistry \& Behavior, 3, 189-194.

WINER, B. J. (1962). Statistical principles in experimental design. New York: McGraw-Hill.

(Manuscript received February 24, 1984; revision accepted for publication April 20, 1985.) 